\title{
Near-tropical subsurface ice on Mars
}

\author{
Mathieu Vincendon, ${ }^{1}$ John Mustard, ${ }^{1}$ François Forget, ${ }^{2}$ Mikhail Kreslavsky, ${ }^{3}$ \\ Aymeric Spiga, ${ }^{4}$ Scott Murchie, ${ }^{5}$ and Jean-Pierre Bibring ${ }^{6}$ \\ Received 19 October 2009; revised 23 November 2009; accepted 2 December 2009; published 12 January 2010.
}

[1] Near-surface perennial water ice on Mars has been previously inferred down to latitudes of about $45^{\circ}$ and could result from either water vapor diffusion through the regolith under current conditions or previous ice ages precipitations. In this paper we show that at latitudes as low as $25^{\circ}$ in the southern hemisphere buried water ice in the shallow $(<1 \mathrm{~m})$ subsurface is required to explain the observed surface distribution of seasonal $\mathrm{CO}_{2}$ frost on pole facing slopes. This result shows that possible remnants of the last ice age, as well as water that will be needed for the future exploration of Mars, are accessible significantly closer to the equator than previously thought, where mild conditions for both robotic and human exploration lie. Citation: Vincendon, M., J. Mustard, F. Forget, M. Kreslavsky, A. Spiga, S. Murchie, and J.-P. Bibring (2010), Near-tropical subsurface ice on Mars, Geophys. Res. Lett., 37, L01202, doi:10.1029/2009GL041426.

[2] While perennial water ice is routinely observed both at the surface and in the subsurface at high latitudes [Kieffer et al., 1976; Boynton et al., 2002; Mitrofanov et al., 2002; Bibring et al., 2004; Mellon et al., 2004; Bandfield and Feldman, 2008; Smith et al., 2009], only subsurface water ice can survive throughout the entire year at mid-latitudes. Evidence for shallow $(<1 \mathrm{~m})$ subsurface water ice has been obtained from observations down to latitudes of about $45^{\circ}$ in both hemispheres [Mellon et al., 2004; Byrne et al., 2009], and deeper buried glaciers have been locally inferred down to $40^{\circ}$ latitude [Holt et al., 2008; Plaut et al., 2009]. It is not clear yet to what extent this subsurface ice has formed under current conditions via water vapor diffusion through the regolith and/or is the remnant of previous ice ages precipitations that occurred at higher obliquities [Mellon and Jakosky, 1995; Head et al., 2003; Schorghofer, 2007; Hudson et al., 2009]. At more equatorward latitudes, morphological observations consistent with the past presence of shallow subsurface water ice have been reported [Squyres and Carr, 1986; Mustard et al., 2001; Head et al., 2003]. It has been suggested that this water ice may be locally preserved [Christensen, 2003], and modeling pre-

\footnotetext{
${ }^{1}$ Department of Geological Sciences, Brown University, Providence, Rhode Island, USA.

${ }^{2}$ Laboratoire de Météorologie Dynamique, Université Paris 6, Paris, France.

${ }^{3}$ Earth and Planetary Sciences, University of California, Santa Cruz, California, USA.

${ }^{4}$ Department of Physics and Astronomy, Open University, Milton Keynes, UK.

${ }_{5}^{5}$ Johns Hopkins University Applied Physics Laboratory, Laurel, Maryland, USA.

${ }^{6}$ Institut d'Astrophysique Spatiale, Université Paris-Sud 11, Orsay, France.
}

Copyright 2010 by the American Geophysical Union. 0094-8276/10/2009GL041426\$05.00 dictions indicate that subsurface water ice could be stable today on pole facing slopes at those latitudes [Aharonson and Schorghofer, 2006]. However, there is no observational evidence.

[3] The OMEGA (Observatoire pour la Minéralogie, l'Eau, les Glaces et l'Activité onboard Mars Express) and CRISM (Compact Reconnaissance Imaging Spectrometer for Mars onboard Mars Reconnaissance Orbiter) near-infrared imaging spectrometers have been observing the surface of Mars since 2004 and 2006 respectively. These instruments measure solar radiation scattered by the surface, mainly in the first upper hundreds of microns. They provide spectral images with a spatial resolution ranging from 20 meters to 5 kilometers and a spectral sampling between $7 \mathrm{~nm}$ and $40 \mathrm{~nm}$. While these data have been widely used to assess the composition of both minerals and condensates on the surface of Mars, they do not provide direct evidence of the properties of the subsurface. Nevertheless, surface conditions are partly driven by the thermal properties of the subsurface. In fact, the current amount of $\mathrm{CO}_{2}$ that condenses as seasonal caps is controlled by the presence of subsurface water ice: high-latitudes water ice in the shallow subsurface is required for global climate models to match the surface pressure data [Haberle et al., 2008]. Condensed $\mathrm{CO}_{2}$ deposits at the surface can be detected in OMEGA and CRISM data using the $1.43 \mu \mathrm{m}$ absorption band [Langevin et al., 2007]. The band depth detection limit at this wavelength is $2 \%$ under ideal conditions and $10 \%$ under less ideal conditions. This detection limits correspond to a photon path length within the ice on the order of 10 $200 \mu \mathrm{m}$ [Schmitt et al., 2004]. Most $\mathrm{CO}_{2}$ ice deposits are therefore detectable using OMEGA and CRISM according to their expected thickness and grain size [Forget et al., 1995].

[4] $\mathrm{CO}_{2}$ ice condenses as a seasonal cap between the pole and about $45^{\circ}$ latitude in the southern hemisphere [Langevin et al., 2007]. However, patches of $\mathrm{CO}_{2}$ ice accumulated thanks to local thermal conditions have been reported at more equatorward latitudes [Schorghofer and Edgett, 2006; Langevin et al., 2007] (Figure 1). To better understand these conditions we have monitored the presence of surface $\mathrm{CO}_{2}$ ice in the southern hemisphere using the OMEGA and CRISM datasets. The spatial and temporal distributions of the detected deposits are shown on Figures 2 and 3 respectively. $\mathrm{CO}_{2}$ ice is detected in late southern fall and winter. The latitudinal stability limit of $\mathrm{CO}_{2}$ ice varies with longitude, with a minimum value of $34^{\circ} \mathrm{S} . \mathrm{CO}_{2}$ ice is less stable at high altitudes (e.g., in Thaumasia) as expected from the decrease of the frost point temperature with elevation. Our observational results generally agree with previous detection of transient bright deposits in visible images which where inferred to be $\mathrm{CO}_{2}$ ice deposits [Schorghofer and Edgett, 2006]. A notable difference is the detection of $\mathrm{CO}_{2}$ ice $10^{\circ}$ of solar longitude earlier in the 


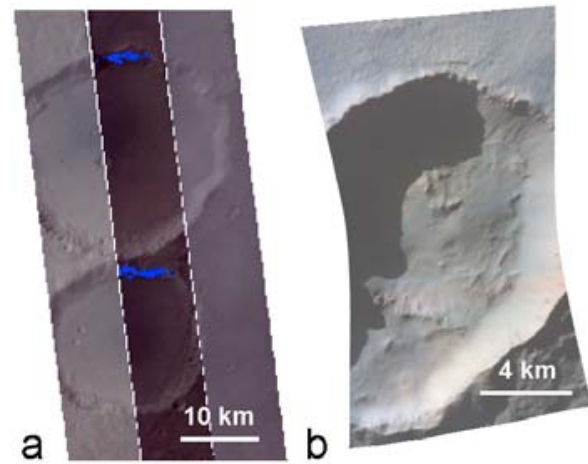

Figure 1. Near-IR observations of crater slopes in southern winter by the CRISM instrument (North is up). (a) Examples of pole-facing slopes with $\mathrm{CO}_{2}$ ice deposits. A low resolution $(230 \mathrm{~m} /$ pix $)$ mosaic of two craters at $40^{\circ} \mathrm{S}$, $157^{\circ} \mathrm{E}$ shows $\mathrm{CO}_{2}$ ice (blue) in (middle) mid-winter $\left(\mathrm{L}_{\mathrm{S}}=\right.$ $\left.147^{\circ}\right)$ but not in (left) early spring $\left(\mathrm{L}_{\mathrm{S}}=200^{\circ}\right)$ and (right) late winter $\left(\mathrm{L}_{\mathrm{S}}=165^{\circ}\right)$. The spatial and seasonal distributions of these $\mathrm{CO}_{2}$ deposits are shown in Figures 2 and 3. (b) Steep pole facing slope $\left(33^{\circ}\right)$ without ice observed at $\mathrm{L}_{\mathrm{S}} 88^{\circ}$ (winter solstice) in a high resolution observation $(34 \mathrm{~m} / \mathrm{pix})$ centered at $32.6^{\circ} \mathrm{S}, 131.2^{\circ} \mathrm{E}$. The lack of $\mathrm{CO}_{2}$ frost at this latitude and season can only be explained by the presence of subsurface water ice that release during winter the heat accumulated in summer.

season. Another difference between our study and these results occurs in the Thaumasia regions $\left(\sim 270^{\circ} \mathrm{E}\right)$ where bright surface ice deposits are composed of water ice and not of $\mathrm{CO}_{2}$ ice according to our near-IR spectroscopy measurements.

[5] We have compared this observed stability pattern with the predictions of a one-dimensional energy balance code derived from the Global Climate Model developed at the LMD [Forget et al., 1999; Spiga and Forget, 2008]. This model has been extensively validated through compar- isons with available spacecraft observations. It calculates the energy balance between the incoming energy fluxes on pole facing slopes (direct sunlight, light scattered and IR radiation emitted and scattered by aerosols and $\mathrm{CO}_{2}$ gas, solar and thermal radiations reflected or emitted by surrounding flat surfaces, heat conducted from the subsurface, and latent heat release when $\mathrm{CO}_{2}$ condenses) and outgoing energy fluxes (thermal IR radiation emitted by the surface, heat conducted into the subsurface, latent heat used for $\mathrm{CO}_{2}$ sublimation). The model also accounts for the sensible heat exchange between the atmosphere and the surface (a minor term due to the low atmospheric pressure). $\mathrm{CO}_{2}$ condensation starts when the surface temperature reaches the $\mathrm{CO}_{2}$ frost point. The presence of $\mathrm{CO}_{2}$ ice then modifies the surface albedo and emissivity. The model is run for 10 years to reach a repeatable annual behavior.

[6] The predicted latitude-season stability pattern obtained from this basic parameterization is compared to observations in Figure 3a (parameters are summarized on Table 1). A strong mismatch is evident: on pole-facing slopes, $\mathrm{CO}_{2}$ ice is expected to be stable down to $22^{\circ} \mathrm{S}$ and should be observed over a period twice longer at $45^{\circ} \mathrm{S}$. This discrepancy implies that a physical source of heat, localized on slopes, has not been taken into account. We have identified three major unknowns in our modeling approach that could significantly impact the results. First, the physical properties of the $\mathrm{CO}_{2}$ ice deposits are not constrained by observations with a good accuracy. Changing the $\mathrm{CO}_{2}$ ice parameters within the range of known properties (Table 1) cannot explain the mismatch, notably because ice properties do not significantly impact the starting date of the condensation. Secondly, steep pole facing slopes in winter are mainly illuminated by the light scattered by the airborne dust particles contrary to flat surfaces. To compute this scattered flux, the LMD model use a robust slope illumination scheme derived from Monte-Carlo simulations [Spiga and Forget, 2008]. However, uncertainties remain in the optical properties of dust particles, as well as in the amount of dust. In addition, the flux scattered toward the

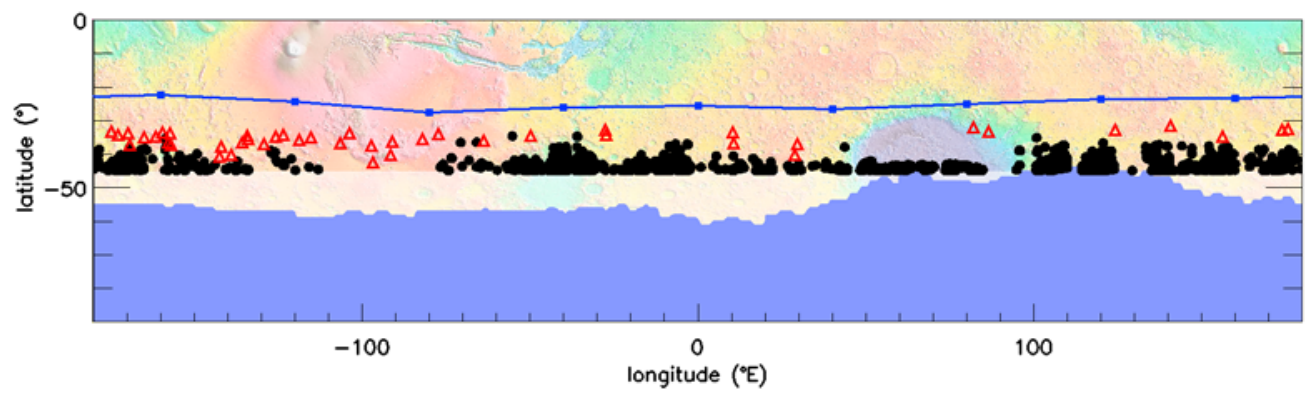

Figure 2. $\mathrm{CO}_{2}$ ice deposits (black points) observed with CRISM and OMEGA at latitudes lower than $45^{\circ} \mathrm{S}$ are shown on a MOLA altimetry map [Smith et al., 1999]. $\mathrm{CO}_{2}$ ice is detected up to $34^{\circ} \mathrm{S}$. Most $\mathrm{CO}_{2}$ deposits are observed on pole facing slopes with angles in the 20-30 range according to topography measurements [Smith et al., 1999; Kreslavsky and Head, 2000]. Deposits observed at the lowest latitudes are in the upper part of that range. Steep $\left(>25^{\circ}\right)$ pole facing crater rim without ice (Figure $1 \mathrm{~b}$ ) observed between $\mathrm{L}_{\mathrm{S}}=100^{\circ}$ and $\mathrm{L}_{\mathrm{S}}=140^{\circ}$ (when ice is stable between $36^{\circ} \mathrm{S}$ and $34^{\circ} \mathrm{S}$ ) at latitudes southern than $32^{\circ} \mathrm{S}$ are also indicated (red triangles). They show that no major observational bias occur in our derived spatial stability limits (except in Hellas due to clouds). The previously well-accepted limit of near-surface ground ice as constrained by low-resolution observations [Mellon et al., 2004] is indicated as a blue-filled area (southern of a limit that range from $60^{\circ} \mathrm{S}$ to $45^{\circ} \mathrm{S}$ ). Our derived local limit below steep pole facing slopes is indicated as a blue line (around $25^{\circ} \mathrm{S}$ ): poleward of $25^{\circ} \mathrm{S}$, water ice is needed in the first meter of the subsurface to explain the low stability of $\mathrm{CO}_{2}$ ice as a function of latitude and season (see Figure 3). 


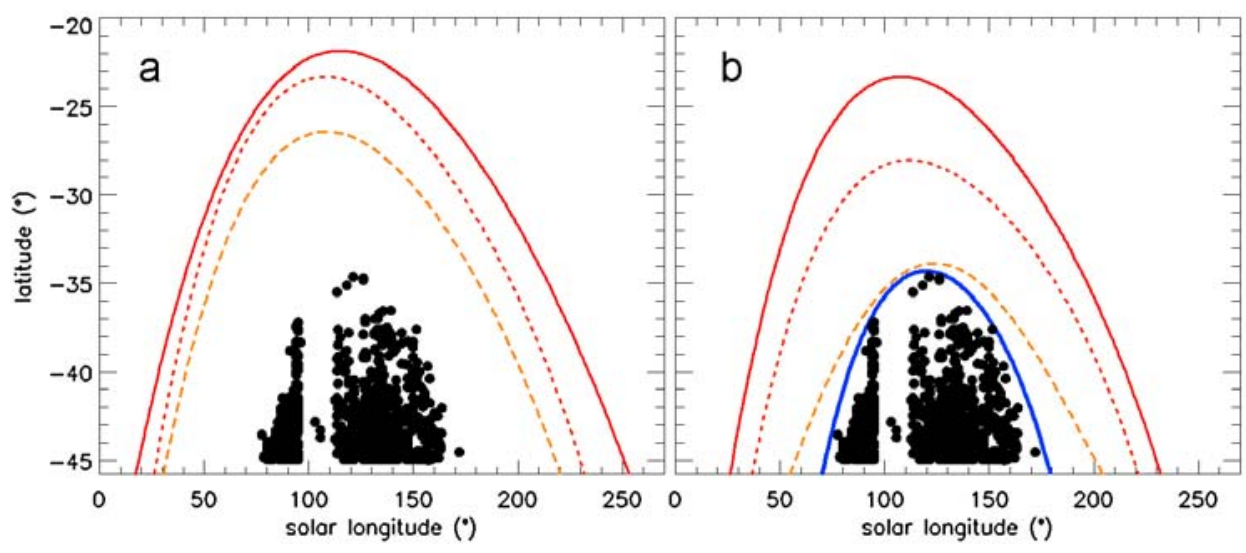

Figure 3. Observed $\mathrm{CO}_{2}$ ice deposits (black points) are shown in a latitude/season diagram, and compared to modeling predictions of the stability limit (lines). The $\mathrm{CO}_{2}$ deposits observed at the edges of the distribution are located on the relatively flat plateau at the east of Hellas. (a) Impact of scattered light contribution. Three dust optical depth scenarios are shown: the standard LMD GCM scenario [Forget et al., 1999] in solid line ( $\tau \sim 0.15$ in winter), the optical depth measured by Spirit [Lemmon et al., 2004] in dotted line ( $\tau \sim 0.23$ once scaled for elevation), and the Opportunity scenario in dashed line $(\tau \sim 0.4)$. Even a high winter optical depth value for the southern hemisphere $(0.4)$ can not explain the observations. The Spirit scenario is used in Figure $3 \mathrm{~b}$ as it is a good proxy for the eastern Hellas plateau [Vincendon et al., 2009]. (b) Impact of ground thermal inertia: From top to bottom, the ground is composed of a single layer with thermal inertia $\mathrm{I}=250 \mathrm{~kg} \mathrm{~K}^{-1} \mathrm{~s}^{-5 / 2}$ (solid line), $\mathrm{I}=600 \mathrm{~kg} \mathrm{~K}^{-1} \mathrm{~s}^{-5 / 2}$ (dotted line), $\mathrm{I}=1180 \mathrm{~kg} \mathrm{~K}^{-1} \mathrm{~s}^{-5 / 2}$ (dashed line). The best fit (thick solid line) is obtained with two layers $\left(\mathrm{I}=250 \mathrm{~kg} \mathrm{~K}^{-1} \mathrm{~s}^{-5 / 2}\right.$ above $\left.\mathrm{I}=2120 \mathrm{~kg} \mathrm{~K}^{-1} \mathrm{~s}^{-5 / 2}\right)$ and with a latitude dependent depth $\left(6 \mathrm{~cm}\right.$ at $45^{\circ} \mathrm{S}, 13 \mathrm{~cm}$ at $35^{\circ} \mathrm{S}$, and an upper limit of $90 \mathrm{~cm}$ at $25^{\circ}$ to extinct $\mathrm{CO}_{2}$ ice $)$. A change in the upper layer inertia significantly modifies the depth retrievals: at $45^{\circ} \mathrm{S}$, the depth is $2 \mathrm{~cm}$ for I $=100 \mathrm{~kg} \mathrm{~K}^{-1} \mathrm{~s}^{-5 / 2}$ and $16 \mathrm{~cm}$ for $\mathrm{I}=400 \mathrm{~kg} \mathrm{~K}^{-1} \mathrm{~s}^{-5 / 2}$; at $35^{\circ} \mathrm{S}$, the depths are $5 \mathrm{~cm}$ and $40 \mathrm{~cm}$ respectively. Using a slope angle of $20^{\circ}$ (instead of $\left.30^{\circ}\right)$ without subsurface ice leads to a model stability limit similar to the dotted line in Figure $3 \mathrm{~b}\left(\mathrm{CO}_{2}\right.$ ice should be stable down to $28^{\circ} \mathrm{S}$ on $20^{\circ}$ slopes).

slope when the sun is below the horizon is not routinely accounted for because radiative transfer calculations are performed using a plane-parallel geometry. Some examples of predictions of the model using different hypotheses for the scattered light contribution are shown on Figure 3a. Increasing the amount of scattered light within the uncertainty range makes it possible to reduce the stability extent of $\mathrm{CO}_{2}$ ice by $5^{\circ}$ of latitude and $50^{\circ}$ of solar longitude, which is not enough to explain the mismatch.

[7] The last unknown is the subsurface thermal flux, controlled by thermal inertia. Higher thermal inertia surfaces store more heat during summer, and release this heat in winter [Haberle et al., 2008]. As shown in Figure 3b, increasing the thermal inertia of the surface and subsurface allows the model to better fit the observations. Thermal inertia higher than $1180 \mathrm{~kg} \mathrm{~K}^{-1} \mathrm{~s}^{-5 / 2}$ is required to bring the stability of $\mathrm{CO}_{2}$ ice to a level consistent with the observations. We can also notice that the inertia must be latitude-dependent (Figure 3b, dashed line), with a higher value around $1500 \mathrm{~kg} \mathrm{~K}^{-1} \mathrm{~s}^{-5 / 2}$ required at $45^{\circ} \mathrm{S}$ compared to $1180 \mathrm{~kg} \mathrm{~K}^{-1} \mathrm{~s}^{-5 / 2}$ at $35^{\circ} \mathrm{S}$. However, the thermal inertia of the surface is typically in the $100-400 \mathrm{~kg} \mathrm{~K}^{-1} \mathrm{~s}^{-5 / 2}$ range on these slopes according to TES (Thermal Emission Spectrometer onboard Mars Global Surveyor) observations

Table 1. Model Parameters Used in Figures 2 and $3^{\mathrm{a}}$

\begin{tabular}{|c|c|c|}
\hline Parameters & Used Value & Explored Range and/or Constraints \\
\hline ice albedo & 0.65 & $\begin{array}{l}0.25-0.65 \text { [Titus et al., 2001; Schorghofer } \\
\text { and Edgett, 2006; Langevin et al., 2007] }\end{array}$ \\
\hline ice emissivity & 1.00 & $0.8-1.0$ [Titus et al., 2001] \\
\hline surface albedo ${ }^{\mathrm{b}}$ & $0.23-0.13$ & TES [Putzig et al., 2005] \\
\hline surface emissivity & 0.95 & $0.90-1.00$ [Bandfield and Feldman, 2008] \\
\hline surface thermal inertia ${ }^{\mathrm{b}}$ & $250 \mathrm{~kg} \mathrm{~K}^{-1} \mathrm{~s}^{-5 / 2}$ & TES [Putzig et al., 2005] \\
\hline subsurface thermal inertia & $2120 \mathrm{~kg} \mathrm{~K}^{-1} \mathrm{~s}^{-5 / 2}$ & water ice $(180 \mathrm{~K})$ \\
\hline slope angle & $30^{\circ}$ & $\begin{array}{c}\text { MOLA [Smith et al., 1999; Kreslavsky and } \\
\text { Head, 2000] }\end{array}$ \\
\hline wind & $20 \mathrm{~m} \mathrm{~s}^{-1}$ & $0-50 \mathrm{~m} \mathrm{~s}^{-1}$ \\
\hline surface pressure $^{\mathrm{b}}$ & annual variations at $37^{\circ} \mathrm{S}, 135^{\circ} \mathrm{E}$ & Global Climate Model [Forget et al., 1999] \\
\hline flat surface temperature ${ }^{\mathrm{b}}$ & annual variations at $152^{\circ} \mathrm{E}$ & Global Climate Model [Forget et al., 1999] \\
\hline aerosols optical depth ${ }^{\mathrm{b}}$ & $\begin{array}{c}\text { Spirit scaled to an } \\
\text { elevation of } 1 \mathrm{~km}(\mathrm{x} 0.75)\end{array}$ & $\begin{array}{l}\text { TES, Spirit and Opportunity [Forget et al., 1999; } \\
\text { Lemmon et al., 2004; Vincendon et al., 2009] }\end{array}$ \\
\hline
\end{tabular}

${ }^{\mathrm{a}}$ If not otherwise indicated.

${ }^{\mathrm{b}}$ Longitude-dependent. 
[Putzig et al., 2005]. A surface inertia above $1180 \mathrm{~kg} \mathrm{~K}^{-1}$ $\mathrm{s}^{-5 / 2}$ for all pole-facing slopes is therefore not possible. The thermal inertias retrieved by TES have been modeled from the daily response of the heated surfaces and are therefore representative of the first few centimeters of the surface only [Putzig et al., 2005], while the first meters of the subsurface affect surface temperatures [Bandfield and Feldman, 2008]. We have therefore modified our model to include two layers in the subsurface of different thermal inertia. This structure is expected if a permafrost layer is present below a dry regolith cover [Hudson et al., 2009; Aharonson and Schorghofer, 2006]. The inertia of the upper layer is set to the mean value of $250 \mathrm{~kg} \mathrm{~K}^{-1} \mathrm{~s}^{-5 / 2}$ as constrained from TES observations, while the lower layer is set to $2120 \mathrm{~kg} \mathrm{~K}^{-1} \mathrm{~s}^{-5 / 2}$, the inertia of water ice at Martian subsurface temperature. Inertias of about $2000 \mathrm{~kg} \mathrm{~K}^{-1} \mathrm{~s}^{-5 / 2}$ are also representative of permafrost or solid bedrock [Fergason et al., 2006; Bandfield and Feldman, 2008]. Simulations where performed assuming various depths for the high inertia layer. A depth varying with latitude from $6 \mathrm{~cm}$ at $45^{\circ} \mathrm{S}$ to $13 \mathrm{~cm}$ at $35^{\circ} \mathrm{S}$ is required to fit the observations (Figure $3 \mathrm{~b}$, thick solid line). This latitude-dependent depth is the counterpart of the latitudedependent inertia that was required in the single layer approach (Figure 3b, dashed line): a shallower depth acts as a higher mean inertia by bringing the buried high inertia layer closer to the surface. Below $34^{\circ} \mathrm{S}$, we can only derived the upper limit of the depth needed to extinct $\mathrm{CO}_{2}$ ice: the depth increases more quickly at those latitudes and reaches $0.9 \mathrm{~m}$ at $25^{\circ} \mathrm{S}$. The latitude dependence of the depth retrieved using our approach agrees very well with the predicted ice table depths on pole facing slopes by an independent study [Aharonson and Schorghofer, 2006]. In contrast mechanisms other than a water ice-rich subsurface to create a two layer thermal inertia surface are not plausible. For example a bedrock layer would need to be uniformly buried in longitude, increasingly buried with latitude, without ever being exposed as it is not seen in thermal infrared data [Bandfield and Feldman, 2008; Putzig et al., 2005]. A definitive argument in favor of the water ice explanation is that the presence or absence of $\mathrm{CO}_{2}$ ice deposits in our dataset is not correlated with the thermal inertia of the upper layer derived with TES observations. This result is expected for a buried water ice rich layer because the ice table depth adjusts to the regolith inertia [Bandfield and Feldman, 2008].

[8] Using different modeling hypotheses within the range of uncertainties (Table 1 and Figure 3) leads to the result that water ice is present within one meter of the surface on all $20-30^{\circ}$ pole facing slope down to about $25^{\circ} \mathrm{S}$ (Figure 2). The relevant thermal depths probed are 2 or 3 meters. Hence, an ice rich layer that thick is implied, which leads to an estimated reservoir of perennial subsurface water ice of about $50-500 \mathrm{~kg} \mathrm{~m}^{-2}$ on steep slopes. Thermal measurements of seasonal temperature variations could help to derive more precise permafrost depths [Bandfield and Feldman, 2008], notably at latitudes lower than $34^{\circ} \mathrm{S}$ where $\mathrm{CO}_{2}$ frost is not observed.

[9] The Mars Science Laboratory (MSL) rover, scheduled in 2011 , is designed to navigate on slopes up to $30^{\circ}$ and will land equatorward of $30^{\circ}$ latitude [Mars Science Laboratory Project, 2007]. Considering that the southern hemisphere combine the widespread occurrence of slopes with near-surface water ice and phyllosilicates deposits that constitute one of the top priority target for future exobiological experiments on Mars, near-surface water ice at midlatitude could be accessible to the next mission to Mars. One of the four candidate landing sites selected so far for MSL, Holden crater, is indeed located at the edge of the subsurface water ice area at $26^{\circ} \mathrm{S}$.

\section{References}

Aharonson, O., and N. Schorghofer (2006), Subsurface ice on Mars with rough topography, J. Geophys. Res., 111, E11007, doi:10.1029/ 2005JE002636.

Bandfield, J. L., and W. C. Feldman (2008), Martian high latitude permafrost depth and surface cover thermal inertia distributions, J. Geophys. Res., 113, E08001, doi:10.1029/2007JE003007.

Bibring, J.-P., et al. (2004), Perennial water ice identified in the south polar cap of Mars, Nature, 428, 627-630, doi:10.1038/nature02461.

Boynton, W. V., et al. (2002), Distribution of hydrogen in the near surface of Mars: Evidence for subsurface ice deposits, Science, 297, 81-85, doi:10.1126/science. 1073722 .

Byrne, S., et al. (2009), Distribution of mid-latitude ground ice on Mars from new impact craters, Science, 325, 1674-1676, doi:10.1126/ science. 1175307.

Christensen, P. R. (2003), Formation of recent Martian gullies through melting of extensive water-rich snow deposits, Nature, 422, 45-48, doi: 10.1038 /nature 01436 .

Fergason, R. L., P. R. Christensen, and H. H. Kieffer (2006), High-resolution thermal inertia derived from the Thermal Emission Imaging System (THEMIS): Thermal model and applications, J. Geophys. Res., 111, E12004, doi:10.1029/2006JE002735.

Forget, F., G. Hansen, and J. B. Pollack (1995), Low brightness temperatures of Martian Polar caps: $\mathrm{CO}_{2}$ clouds or low surface emissivity?, J. Geophys. Res., 100, 21,219-21,234, doi:10.1029/95JE02378.

Forget, F., et al. (1999), Improved general circulation models of the Martian atmosphere from the surface to above $80 \mathrm{~km}$, J. Geophys. Res., 104, 24,155-24,176, doi:10.1029/1999JE001025.

Haberle, R. M., et al. (2008), The effect of ground ice on the Martian seasonal $\mathrm{CO}_{2}$ cycle, Planet. Space Sci., 56, 251-255, doi:10.1016/ j.pss.2007.08.006.

Head, J. W., J. F. Mustard, M. A. Kreslavsky, R. E. Milliken, and D. R. Marchant (2003), Recent ice ages on Mars, Nature, 426, 797-802, doi:10.1038/nature02114.

Holt, J. W., et al. (2008), Radar sounding evidence for buried glaciers in the southern mid-latitudes of Mars, Science, 322, 1235-1238, doi:10.1126/ science. 1164246 .

Hudson, T. L., O. Aharonson, and N. Schorghofer (2009), Laboratory experiments and models of diffusive emplacement of ground ice on Mars, J. Geophys. Res., 114, E01002, doi:10.1029/2008JE003149.

Kieffer, H. H., S. C. Chase, T. Z. Martin, E. D. Miner, and F. D. Palluconi (1976), Martian north pole summer temperatures: Dirty water ice, Science, 194, 1341-1344, doi:10.1126/science.194.4271.1341.

Kreslavsky, M. A., and J. W. Head (2000), Kilometer scale roughness of Mars: Result from MOLA data analysis, J. Geophys. Res., 105, 26,695-26,711, doi:10.1029/2000JE001259.

Langevin, Y., et al. (2007), Observations of the South seasonal cap of Mars during retreat in 2004-2006 by the OMEGA visible/NIR imaging spectrometer on board Mars Express, J. Geophys. Res., 112, E08S12, doi:10.1029/2006JE002841.

Lemmon, M. T., et al. (2004), Atmospheric imaging results from the Mars Exploration Rovers: Spirit and Opportunity, Science, 306, 1753-1756, doi: $10.1126 /$ science. 1104474 .

Mars Science Laboratory Project (2007), MSL landing site selection: User's guide to engineering constraints, version 4.5.1, Jet Propul. Lab., Pasadena, Calif.

Mellon, M. T., and B. M. Jakosky (1995), The distribution and behavior of Martian ground ice during past and present epoch, J. Geophys. Res., 100, 11,781-11,799, doi:10.1029/95JE01027.

Mellon, M. T., W. C. Feldman, and T. H. Prettyman (2004), The presence and stability of ground ice in the southern hemisphere of Mars, Icarus, 169, 324-340, doi:10.1016/j.icarus.2003.10.022.

Mitrofanov, I., et al. (2002), Maps of subsurface hydrogen from the High Energy Neutron Detector, Mars Odyssey, Science, 297, 78-81, doi:10.1126/science. 1073616 .

Mustard, J. F., C. D. Cooper, and M. K. Rifkin (2001), Evidence for recent climate change on Mars from the identification of youthful near-surface ground ice, Nature, 412, 411-414, doi:10.1038/35086515.

Plaut, J. J., et al. (2009), Radar evidence for ice in lobate debris aprons in the mid-northern latitudes of Mars, Geophys. Res. Lett., 36, L02203, doi:10.1029/2008GL036379. 
Putzig, N. E., M. T. Mellon, K. A. Kretke, and R. E. Arvidson (2005), Global thermal inertia and surface properties of Mars from the MGS mapping mission, Icarus, 173, 325-341, doi:10.1016/j.icarus. 2004.08.017.

Schmitt, B., S. Douté, F. Altieri, G. Bellucci, and OMEGA (2004), Physical state and composition of Mars polar caps and seasonal condensations by radiative transfer modelling of visible-IR spectra from OMEGA/MEX observations, Bull. Am. Astron. Soc., 36, 1137.

Schorghofer, N. (2007), Dynamics of ice ages on Mars, Nature, 449, 192-194, doi:10.1038/nature06082.

Schorghofer, N., and K. S. Edgett (2006), Seasonal surface frost at low latitudes on Mars, Icarus, 180, 321-334, doi:10.1016/j.icarus.2005. 08.022 .

Smith, D. E., et al. (1999), The global topography of Mars and implications for surface evolution, Science, 284, 1495-1503, doi:10.1126/science. 284.5419.1495.

Smith, P. H., et al. (2009), $\mathrm{H}_{2} \mathrm{O}$ at the Phoenix landing site, Science, 325, 58-61, doi:10.1126/science. 1172339.

Spiga, A., and F. Forget (2008), Fast and accurate estimation of solar irradiance on Martian slopes, Geophys. Res. Lett., 35, L15201, doi:10.1029/2008GL034956.

Squyres, S. W., and M. H. Carr (1986), Geomorphic evidence for the distribution of ground ice on Mars, Science, 231, 249-252, doi:10.1126/science.231.4735.249.
Titus, T. N., H. H. Kieffer, K. F. Mullins, and P. R. Christensen (2001), TES premapping data: Slab ice and snow flurries in the Mars north polar night, J. Geophys. Res., 106, 23,181-23,196, doi:10.1029/2000JE001284.

Vincendon, M., et al. (2009), Yearly and seasonal variations of low albedo surfaces on Mars in the OMEGA/MEx dataset: Constraints on aerosols properties and dust deposits, Icarus, 200, 395-405, doi:10.1016/ j.icarus.2008.12.012.

J.-P. Bibring, Institut d'Astrophysique Spatiale, Université Paris-Sud 11 Bât 120-121, F-91405 Orsay CEDEX, France.

F. Forget, Laboratoire de Météorologie Dynamique, Université Paris 6, BP 99, 4, place Jussieu, F-75005 Paris CEDEX 05, France.

M. Kreslavsky, Earth and Planetary Sciences, University of California, 1156 High St., Santa Cruz, CA 95064, USA.

S. Murchie, Johns Hopkins University Applied Physics Laboratory, 11100 Johns Hopkins Rd., Laurel, MD 20723, USA

J. Mustard and M. Vincendon, Department of Geological Sciences, Brown University, 324 Brook St., Providence, RI 02912, USA. (mathieu vincendon@brown.edu)

A. Spiga, Department of Physics and Astronomy, Open University, PO Box 197, Milton Keynes, MK7 6BJ, UK. 